\title{
Research Paper: \\ Effects of Extraction Solvents on the Antioxidant and Phytochemical Activities of Manihot Esculenta Leaves
}

\author{
Israel O. Okoro ${ }^{1^{*}}$ iD
}

${ }^{1}$. Department of Biochemistry, Faculty of Science, Delta State University, Abraka, Delta State, Nigeria.

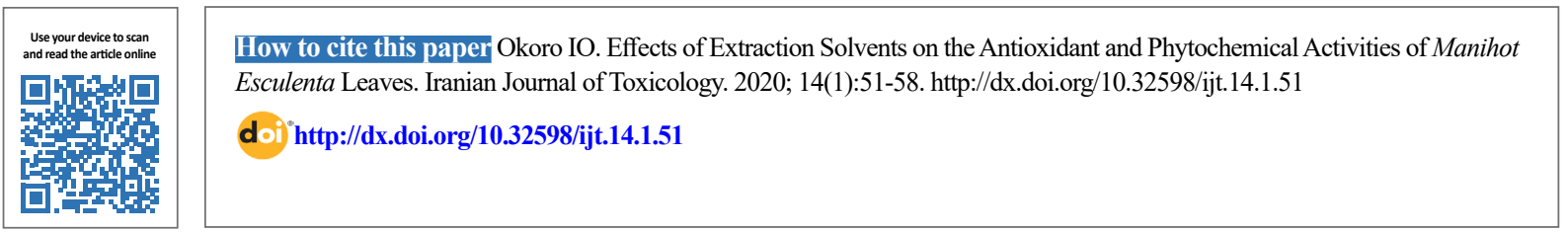

\section{(1) (8)}

Article info:

Received: 07 Aug 2019

Accepted: 05 Dec 2019

Online Published: 10 Jan 2020

* Corresponding author:

Isreal O. Okoro, PhD.

Address: Department of Biochemistry, Faculty of Science, Delta State University, Abraka, Delta State, Nigeria. E-mail: israelik@yahoo.com

\section{A BSTRACT}

Background: Plants contain diverse phytochemicals with different solubility levels, depending on their molecular charges and polarity. This study was conducted to examine the effects of three extraction solvents in their pure and aqueous forms: absolute petroleum ether, acetone and ethanol on the phytochemical profile and antioxidant activities of Manihot esculenta leaves extracts.

Methods: The preliminary phytochemical investigations were performed, using standard procedures. The in vitro antioxidant properties were estimated by: 1,1-Diphenyl-2-Picryl-Hydrazyl (DPPH), Hydrogen peroxide $\left(\mathrm{H}_{2} \mathrm{O}_{2}\right)$ scavenging activity, Ferric Reducing Antioxidant Power (FRAP) and Ferric Thiocyanate (FTC).

Results: The phytochemical analyses revealed the occurrence of an array of compounds: alkaloids, flavonoids, cardiac glycosides, tannin phenols, saponins and anthraquinones, the concentration of which varied with the solvent type. A considerable presence of all phytochemicals was found in the aqueous ethanol. The extracts from pure solvents were much less effective against DPPH synthetic radical than those $50 \%$ diluted. The petroleum ether extract provided the least antiradical activity, while the aqueous ethanol was the richest. The scavenging effect of the extracts on $\mathrm{H}_{2} \mathrm{O}_{2}$ varied in this order: $50 \%$ ethanol $>$ absolute ethanol $>$ ascorbic acid $>50 \%$ acetone $>$ absolute acetone $>50 \%$ petroleum ether $>$ absolute petroleum ether. Similarly, the results of the FRAP and FTC methods agreed largely with those of the DPPH and $\mathrm{H}_{2} \mathrm{O}_{2}$. Thus, the results of antioxidant activity positively correlated with the phytochemical results, with the aqueous ethanol showing the maximum activity overall.

Conclusion: The results indicated that the extraction solvents considerably affected the phytochemical contents and the antioxidant activities of the tested extracts. These extracts can potentially serve as the alternative sources of natural antioxidant preparations.

Keywords: Phytochemicals; Antioxidant; DPPH; $\mathrm{H}_{2} \mathrm{O}_{2}$; FRAP; FTC

\section{Introduction}

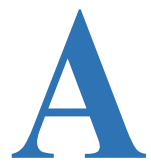

Free radical is defined as an atom or molecule with unpaired electrons. Reactive Oxygen Species (ROS), like oxygen singlets, hydroxyl ions, superoxide ions and hydrogen peroxide, are potent reactive and toxic molecules, generated routinely in all cells dur- ing metabolism [1]. The ROS cause serious oxidative injury to proteins, enzymes, lipids and DNA strands through peroxidation and covalent bnding, leading to tissue injury [2]. Free radicals are associated with the development of different conditions, such as inflammation, cancer and neurodegeneration, hence justifying numerous studies on the effects of antioxidants in the prevention and treatment of various disease processes [3]. 
An antioxidant molecule works by slowing down or preventing oxidation of other molecules unlike oxidation that involves electron transfers from one substance to an oxidizing agent [2]. Oxidation reactions generate free radicals, which kick start the chain reactions leading to cellular damages [1]. An antioxidant serves to terminate these chain reactions by eliminating free radical intermediates and stop other oxidants from oxidizing beneficial molecules [3].

Natural and synthetic antioxidants, such as butylated hydroxyl anisol, butylated hydroxyl toluene and tetra-butylhydro-quinine, act by scavenging free radicals [4]. However, synthetic antioxidants are not favored because of concerns over their safety; structural instability and carcinogenicity [4]. In general, synthetic antioxidants are mostly harmful to human health [5]. In contrast, natural antioxidants, such as phytochemicals, are safer alternatives than the synthetic ones since they offer various therapeutic properties and are devoid of known side effects [5]. In recent years, plant phytochemicals have been widely investigated for their protective effects against various chronic degenerative diseases and are known for their therapeutic potentials as antimutagenic, anticancer and antimicrobial effects. Therefore, they are increasingly in demand [6].

Manihot esculenta Crantz (M. esculenta), a widely grown tropical plant, is greatly valued for its nutritional and medicinal properties [7]. While M. esculenta is known for its positive qualities, which explain its extensive cultivation, there are a number of severe limitations associated with it. This plant contains various bioactive compounds, such as cyanogenic glycosides that are injurious to human health [7]. During its breakdown, this plant releases Hydrogen Cyanide $(\mathrm{HCN})$, which is toxic to humans [7]. Consequently, the consumption of inadequately processed $\mathrm{M}$. esculenta can lead to serious health complications and even death [8].

Longer processing techniques, such as grating, drying, fermenting and pounding the tubers to powder or granular products are used in Africa and Latin America, where high cyanide contents are found in tubers of the plant [7]. To reduce the toxicity of $\mathrm{M}$. esculenta leaves before consumption, pounding followed by boiling has been recommended [7]. Another method commonly used to remove the cyanogens in $\mathrm{M}$. esculenta leaves involves pounding them until they are well macerated, and then washing the material twice in water double their weight to reduce the cyanide content to $8 \%$ [9]. Extra washing has been reported to reduce the cyanide content even to $3 \%$ [9].

The leaves and seeds of $\mathrm{M}$. esculenta are traditionally used to relieve hemorrhoids, headache, fever and rheumatic conditions. Also, in Nigeria, the leaves are used to treat ringworms, abscesses, tumors, sores and conjunctivitis [10]. Various beneficial properties, such as the nutritional value, phenolic and flavonoid contents, antioxidant and antiradical properties, inhibitory potential against pancreatic lipase and xanthine oxidase of $\mathrm{M}$. esculenta leaf extracts have been reported $[11,12]$. However, environmental factors are said to influence the types, contents and antioxidant activities of the extracts [13].

Also, extraction solvents have been reported to significantly affect the phytochemicals and antioxidant activities of this plant [14]. Further, the ability to dissolve the antioxidant compounds has been reported to be influenced by the solvent polarity [15]. Sultana et al. [16] reported that higher contents of phenolic and antioxidant activity of the plant material are obtained from aqueous organic solvents rather than the absolute solvents. Therefore, this study was designed to evaluate the best solvent with the highest phytochemical and antioxidant activities of M. esculenta, using three solvent systems.

\section{Materials and Methods}

Extraction Solvents: The following three solvents were used in this study:

Petroleum ether in water $(50: 50 \mathrm{v} / \mathrm{v})$;

Ethanol in water $(50: 50 \mathrm{v} / \mathrm{v})$;

Acetone in water $(50: 50 \mathrm{v} / \mathrm{v})$

The absolute forms of the above solvents were also used separately in the extraction processes.

The chemicals and reagents included: 1, 1-Diphenyl2-Picrylhydrazyl (DPPH), Dimethyl Sulfoxide (DMSO), ascorbic acid, Linoleic acid, ethanol, acetone, and petroleum ether were supplied by Sigma-Aldrich (St. Louis, MO, USA). Sodium hydroxide, potassium hydroxide, acetic anhydride, sodium carbonate, sodium acetate were obtained from Baker (The Netherlands). All of the chemicals and solvents were of analytical grades.

Collection and Treatment: The leaves of M. esculenta plant were collected from the main campus of the Delta State University and authenticated at the Department of Plant Science, University of Benin, Benin City, Edo StateNigeria. The plant samples were given the voucher number: UBHM372. The leaves were properly washed with water three times, and air-dried for two weeks in the shade. They were pulverized in a pestle and mortar. Fifty grams of leaves were extracted at room temperature in $200 \mathrm{ml}$ of $50 \%$ etha- 
nol for $24 \mathrm{~h}$. The procedure was repeated for $24 \mathrm{~h}$, after which, the combined extracts were concentrated to dryness at $40^{\circ} \mathrm{C}$ under vacuum and refrigerated until further analyses. The extraction processes were also repeated separately with the absolute forms of petroleum ether, ethanol and acetone, and the resultant extracts were refrigerated.

Phytochemical Screening: The preliminary qualitative phytochemical test was performed to detect the presence of alkaloids, tannins, saponins, flavonoids, cardiac glycoside, phenols and anthraquinone, using standard procedures as described previously [17-19]. All phytochemical and antioxidant samples were examined in triplicate throughout this study.

\section{Antioxidant properties}

Radical Scavenging Activity: The radical scavenging activity of the M. esculenta leaves extracts were evaluated by the 1,1-Diphenyl-2-Picryl-Hydrazyl (DPPH) method, as described earlier [20]. The percentage of the scavenging activity was calculated using the following equation: Percent scavenging of $\mathrm{DPPH}=[(\mathrm{A} 0-\mathrm{A} 1) / \mathrm{A} 0] \times 100$.

Where $\mathrm{A} 0=$ absorbance of the control, and $\mathrm{A} 1=$ absorbance of the extracts.

Hydrogen Peroxide Scavenging Activity: The percent scavenging of $\mathrm{H}_{2} \mathrm{O}_{2}$ was estimated by the following equation: Percent scavenging activity of $\mathrm{H}_{2} \mathrm{O}_{2}=[(\mathrm{A} 0$ $\mathrm{A} 1) / \mathrm{A} 0] \times 100$. Where $\mathrm{A} 0$ and $\mathrm{A} 1$ were the absorbance of the control and the test extracts, respectively [21].
Ferric Reducing Antioxidant Power (FRAP) Assay: The ferric reducing antioxidant capacity of the extracts was evaluated as described earlier [22]. An increase in the absorbance of the reaction mixture constituted a rise in the reducing capacity.

Ferric Thiocyanate (FTC) in Linoleic Acid System: The antioxidant activity of the M. esculenta leaves extracts was estimated by the linoleic acid system, as described previously [23]. An increase in the absorbance of the reaction mixture represented a rise in the linoleic acid peroxidation capacity.

Statistical Analyses: In this paper, the data are presented as the Mean $\pm \mathrm{SD}$. One-way Analyses of Variance (ANOVA) with Tukey post hoc test was used to compare the differences among the extract samples at $\mathrm{P}<0.05$.

\section{Results}

Radical Scavenging Activity: The results of DPPH radical scavenging activity of the extract samples are shown in Figure 1. The pure solvent form of petroleum ether was significantly less potent against DPPH synthetic radical scavenging than its $50 \%$ aqueous preparation. With respect to the antiradical activity, the ethanol extracts were the most potent while the acetone extracts had moderate activity. Regardless of the solvents used, the DPPH scavenging activities of the extracts were concentration-dependent. Thus, the best antiradical activity was obtained from the extract of absolute ethanol (IC50 $=29.49 \pm 1.02$ ), while the extract from absolute petroleum ether gave the highest IC50 value (71.41 \pm 2.68$)$, indicating its poor scavenging activity.

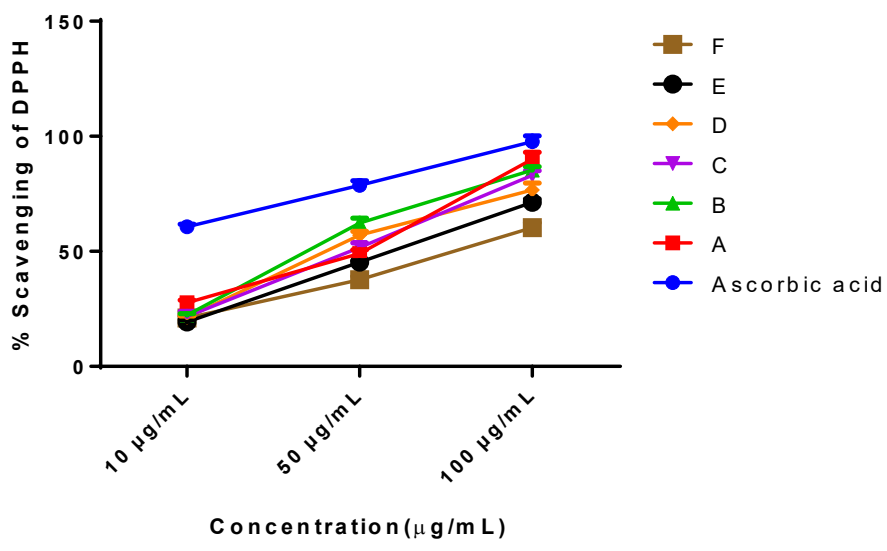

Figure 1. DPPH free radical scavenging activity of different solvent extracts of M. esculenta and ascorbic acid. Results: Mean \pm SD $(n=3)$

$\mathrm{A}=$ Aqueous ethanol (ethanol: water 50:50 v/v); $\mathrm{B}=$ Absolute ethanol; $\mathrm{C}=$ Aqueous acetone (acetone: water 50:50 v/v); $\mathrm{D}=$ Absolute acetone; $\mathrm{E}=$ Aqueous petroleum ether (petroleum ether: water 50:50 v/v), and $\mathrm{F}=$ Absolute petroleum ether 


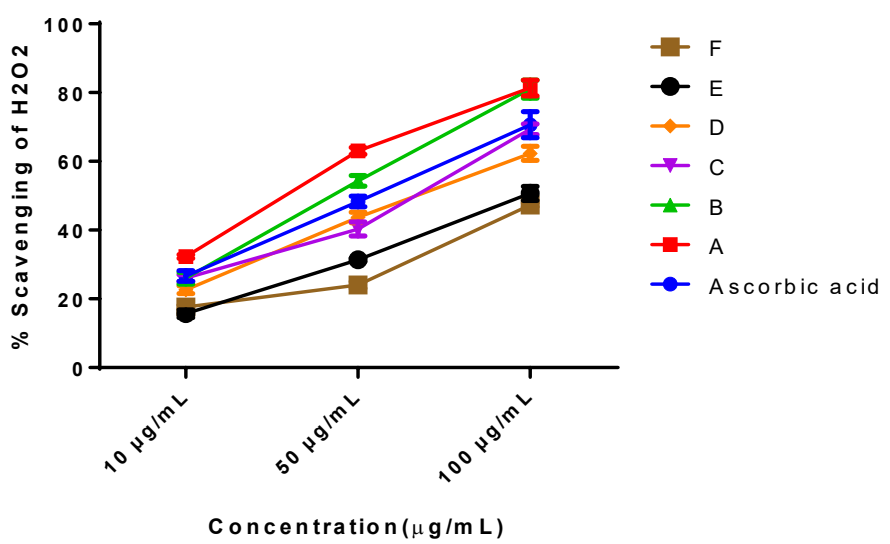

Figure 2. $\mathrm{H}_{2} \mathrm{O}_{2}$ radical scavenging activity of different solvent extracts of $\mathrm{M}$. esculenta and ascorbic acid Results: Mean \pm SD $(n=3)$

$\mathrm{A}=$ Aqueous ethanol (ethanol: water 50:50 v/v); B = Absolute ethanol; $\mathrm{C}=$ Aqueous acetone (acetone: water $50: 50 \mathrm{v} / \mathrm{v}$ ); $\mathrm{D}=$ Absolute acetone; $\mathrm{E}=$ Aqueous petroleum ether (petroleum ether: water 50:50 v/v); and $\mathrm{F}=$ Absolute petroleum ether

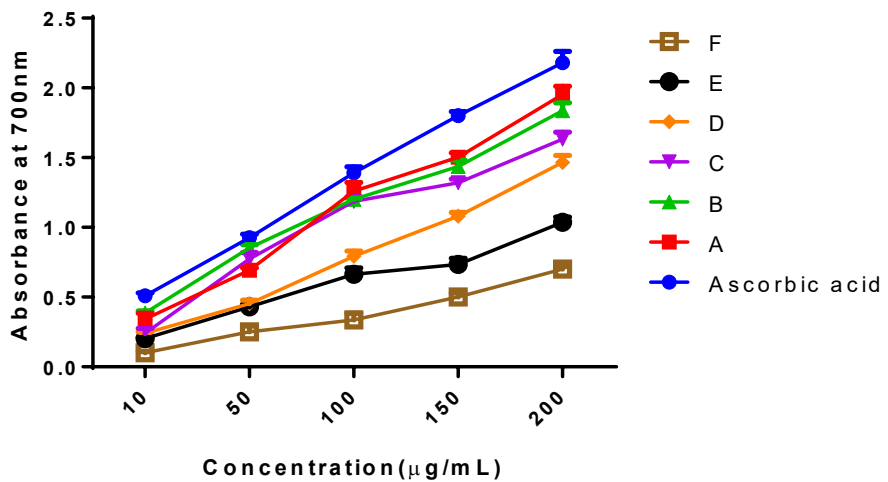

Figure 3. Ferric reducing antioxidant power (FRAP) of different solvent extracts of M. esculenta and ascorbic acid Results: Mean \pm SD $(\mathrm{n}=3)$

$\mathrm{A}=$ aqueous ethanol (ethanol: water 50:50 v/v); $\mathrm{B}=$ absolute ethanol; $\mathrm{C}=$ aqueous acetone (acetone: water 50:50 v/v); $\mathrm{D}=$ absolute acetone; $\mathrm{E}=$ aqueous petroleum ether (petroleum ether: water $50: 50 \mathrm{v} / \mathrm{v}$ ), and $\mathrm{F}=$ absolute petroleum ether

Table 1. IC50 in DPPH and $\mathrm{H}_{2} \mathrm{O}_{2}$ radical scavenging activities of different solvent extracts of M. esculenta and ascorbic acid

\begin{tabular}{cccccccc}
\hline & \multicolumn{7}{c}{ Mean \pm SD } \\
\cline { 2 - 8 } & AA 50 & A & B & C & D & E & F \\
\hline DPPH & $6.23 \pm 0.6$ & $31.77 \pm 2.2$ & $29.49 \pm 1.0$ & $36.75 \pm 2.8$ & $35.77 \pm 1.5$ & $49.18 \pm 1.9$ & $71.41 \pm 2.7$ \\
$\mathrm{H}_{2} \mathrm{O}_{2}$ & $41.80 \pm 0.5$ & $23.88 \pm 1.2$ & $32.60 \pm 2.1$ & $51.57 \pm 2.6$ & $58.75 \pm 5.5$ & $110.78 \pm 12.2$ & $154.83 \pm 5.0$ \\
\hline
\end{tabular}

Mean \pm SD $(n=3)$

$\mathrm{AA}=$ Ascorbic acid; $\mathrm{A}=$ Aqueous ethanol (ethanol: water 50:50 v/v); $\mathrm{B}=$ Absolute ethanol; $\mathrm{C}=$ Aqueous acetone (acetone: water $50: 50 \mathrm{v} / \mathrm{v}$ ); $\mathrm{D}=$ Absolute acetone; $\mathrm{E}=$ Aqueous petroleum ether (petroleum ether: water 50:50 v/v); $\mathrm{F}=$ Absolute petroleum ether 


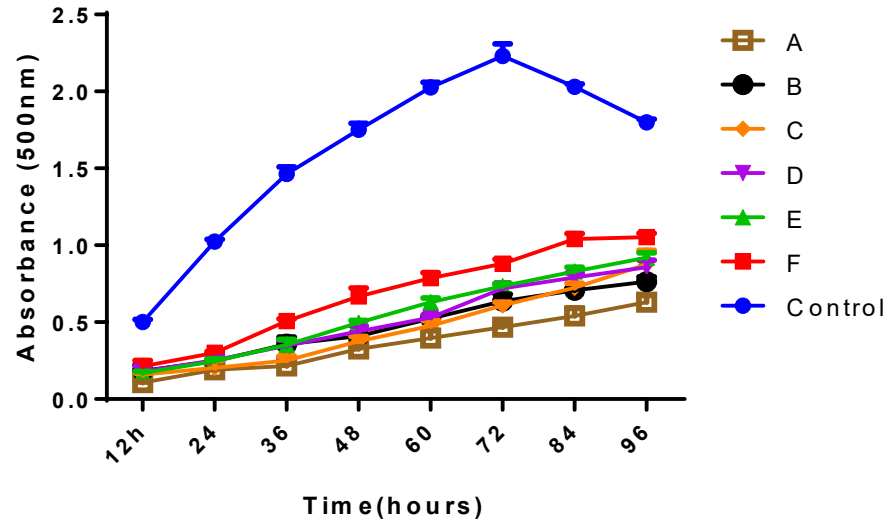

Figure 4. Antioxidant activity of different solvent extracts of M. esculenta by Ferric Thiocyanate (FTC) method

Results: Mean \pm SD $(n=3)$

$\mathrm{A}=$ Aqueous ethanol (ethanol: water 50:50 v/v); $\mathrm{B}=$ Absolute ethanol; $\mathrm{C}=$ Aqueous acetone (acetone: water 50:50 v/v); D = Absolute acetone; $\mathrm{E}=$ Aqueous petroleum ether (petroleum ether: water 50:50 v/v), and $\mathrm{F}=$ Absolute petroleum ether.

Hydrogen Peroxide Scavenging Activity: As shown in Figure 2, the scavenging effect of the extracts on hydrogen peroxide was concentration-dependent (10-100 $\mu \mathrm{g} / \mathrm{ml})$. The extracts obtained from the $50 \%$ and absolute ethanol displayed even stronger $\mathrm{H}_{2} \mathrm{O}_{2}$ scavenging activity (IC50 $=23.88 \pm 1.21$ and $32.60 \pm 2.07$ ) than that from the standard, ascorbic acid (IC $50=41.80 \pm 0.55$ ). As shown in Table 1, the scavenging activities of the extracts from the $50 \%$ and absolute acetone were IC50 $=51.57 \pm 2.63$ and $58.75 \pm 5.54$, respectively.

The IC50 values of the extracts in scavenging hydrogen peroxide varied significantly $(\mathrm{P}<0.05)$. In terms of the IC50 values, the scavenging activities of the extracts obtained from various solvents and the standard ascorbic acid against hydrogen peroxide were in this order: $50 \%$ ethanol $>$ absolute ethanol $>$ ascorbic acid $>$ $50 \%$ acetone $>$ absolute acetone $>50 \%$ petroleum ether $>$ absolute petroleum ether.

Total Antioxidant Activity: The antioxidant activities of the M. esculenta leaves extracts, as evaluated by the FRAP assay, were dependent on their capacity to reduce ferric ions to their ferrous form. As shown in Figure 3, the results revealed that the ethanol extracts had significantly higher FRAP values than those obtained for the acetone and petroleum ether extracts $(\mathrm{P}<0.05)$. The antioxidant activity of the absolute petroleum ether was the lowest among other extracts.

Ferric Thiocyanate (FTC) in Linoleic Acid System: Figure 4 represents the time-course (12-96 h) curves of

Table 2. Preliminary qualitative phytochemical analysis of the six extracts of M. esculenta leaves extracts

\begin{tabular}{|c|c|c|c|c|c|c|c|}
\hline $\mathbf{S} / \mathbf{N}$ & Phytochemical & $\begin{array}{c}\text { Petroleum } \\
\text { Ether }\end{array}$ & $\begin{array}{l}50 \% \\
\text { Ether }\end{array}$ & $\begin{array}{c}\text { Pure } \\
\text { Acetone }\end{array}$ & $\begin{array}{c}50 \% \\
\text { Acetone }\end{array}$ & $\begin{array}{c}\text { Pure } \\
\text { Ethanol }\end{array}$ & $50 \%$ Ethanol \\
\hline 1 & Alkaloids & + & ++ & ++ & +++ & ++ & +++ \\
\hline 2 & Saponins & - & - & - & + & + & +++ \\
\hline 3 & Flavonoids & + & ++ & + & ++ & ++ & +++ \\
\hline 4 & Tannins & + & + & + & ++ & ++ & +++ \\
\hline 5 & Cardiac glycosides & + & ++ & + & + & ++ & +++ \\
\hline 6 & Phenol & - & + & - & + & + & ++ \\
\hline 7 & Anthraquinones & - & - & - & + & + & ++ \\
\hline
\end{tabular}

Concentration of Phytochemicals: ${ }^{+++}$High; ${ }^{++}$Moderate; ${ }^{+}$Low; - Absent 
the antioxidant activity of the M. esculenta leaves extracts versus the controls by FTC method. The results demonstrated that all extracts had noticeable antioxidant activities, which progressed over time. The order of increase in the absorbance at $96 \mathrm{~h}$ incubation was as follows: Control $>$ petroleum ether $>50 \%$ petroleum ether $>$ absolute acetone $>50 \%$ acetone $>$ absolute ethanol $>50 \%$ ethanol. However, the ranking order for the inhibition efficiency of the extracts and controls was reverse, and agreed with that seen in the FRAP method above $(\mathrm{P}<0.05)$. Among the extracts, the lowest absorbance was noted for the 50\% ethanol extract and peroxide formation at the observed intervals.

Effects of Solvents on Phytochemicals: The qualitative phytochemical analyses showed high concentration of alkaloids, tannins, saponins, flavonoids, cardiac glycoside and low concentration of phenol and anthraquinone in the $50 \%$ ethanol (Table 2). Similarly, all of the phytochemicals were detected in the $50 \%$ petroleum ether extracts except for saponins and anthraquinone. Also, there were low concentration of all of the seven phytochemicals in the absolute ethanol and 50\% acetone extracts. Conversely, saponins, phenols and anthraquinones were absent in the absolute acetone extract. Also, low concentrations of alkaloids, flavonoids, tannins and cardiac glycoside were found in the petroleum ether extract. The presence of all tested phytochemicals per solvent types was in the following order: $50 \%$ ethanol $>$ absolute ethanol $>50 \%$ acetone $>$ absolute acetone $>50 \%$ petroleum ether $>$ absolute petroleum ether

\section{Discussion}

The preliminary qualitative phytochemical evaluation of the M. esculenta leaves revealed the presence of alkaloids, cardiac glycosides, flavonoids, phenols, saponins, anthraquinone and tannins. These secondary metabolites have been reported to have numerous therapeutic and biological properties $[24,25]$. The results showed that the aqueous solvents were more effective than the pure ones in terms of the phytochemical contents and the antioxidant activities they exhibited.

In the present study, the extracts exhibited concentration dependent (10-100 $\mu \mathrm{g} / \mathrm{mL})$ and substantial scavenging effects on the DPPH radical activity. A similar trend of DPPH free radical scavenging activity has also been reported earlier [26]. Among the different solvent extracts tested, the ethanol extracts of M. esculenta leaves exhibited the highest DPPH radical scavenging activity. This could have been as a result of the presence of higher content of flavonoids, essential biocompounds, required for the scavenging activity of the extracts. Next to ethanol, the acetone extract of M. esculenta showed effective DPPH scavenging activity, which might also be ascribed to the presence of tannins and phenolics in the extracts. This observation agrees with earlier reports that found higher antioxidant capacities were noted with highly polar solvents than for those with low polarity [11].

The DPPH assay is a common spectrophotometric technique used for determining the activity of antioxidants. The advantage of this process is that the antioxidant activity is usually measured at an ambient temperature, so the danger of heat-induced breakdown of the tested molecule is eliminated. Free radical scavenging is the known mechanisms through which lipid oxidation is inhibited by antioxidants [27]. Disparities in the polarity of antioxidants may be the reason for the observed variations in the activities. Besides, solvent polarity is known to play a vital role in rising solubility of phenolic biocompounds [28].

The scavenging effect of M. esculenta extracts on $\mathrm{H}_{2} \mathrm{O}_{2}$ was concentration-dependent. The $50 \%$ and absolute ethanol extracts displayed even stronger $\mathrm{H}_{2} \mathrm{O}_{2}$ scavenging activity than the standard ascorbic acid. The activities of 50\% and absolute acetone were fairly moderate, while the petroleum ether extracts were least effective in scavenging hydrogen peroxide compared to the other extracts. Hydrogen peroxide naturally occurs at low concentrations in the human body, air, water, plants, food and microorganisms [29].

It is promptly decomposed into water and oxygen, which may then produce hydroxyl radicals $(\mathrm{OH})$, capable of initiating lipid peroxidation and DNA damage. Therefore, the observed effect of the ethanol extracts of M. esculenta efficiently scavenging hydrogen peroxide may be attributed to the presence of phenolic groups that donate electrons to hydrogen peroxide, thereby neutralizing it into water [5]. Solvents, like ethanol, methanol and their mixtures with different amounts of water have been used in the extraction of phenolics, particularly from plant materials [30]. It has also been reported that changes in solvent polarity affect their ability to dissolve antioxidant compounds, thereby altering or influencing the estimation of their activity [15].

In this study, the antioxidant activities of M. esculenta leaves extracts were also assessed by the FRAP method, which was based on the capacity to reduce ferric ions to their ferrous form. The results showed that ethanol extracts had reasonably higher FRAP values than the acetone extracts, which in turn displayed higher activity than the petroleum ether extracts. Thus, the antioxidant activity of $50 \%$ and absolute petroleum ether preparations were the lowest. The highest antioxidant activity was exhibited by the standard ascorbic acid. Thus, the total antioxidant capacity of M. esculenta leaves was signifi- 
cantly higher in the ethanol extracts than in other extracts, and varied according to the solvent type. There were considerable differences among the total antioxidant activity of all extracts, and between controls and the extracts. This observed activity may be ascribed to the presence of secondary metabolites, such as phenols and flavonoids in M. esculenta. There was strong association between the presence of phenols, tannins and flavonoids detected during the phytochemical screening and the observed radical scavenging activity, demonstrating that the phytochemical constituents may be the major contributors to the antioxidant potential of M. esculenta [31, 32].

The results obtained from the FTC method indicate that all extracts of the plant had a significant measure of antioxidant activity, whereby it increased over time for the tested samples. The inhibition efficacy noticed in this method agreed largely with that observed in the FRAP method. Of the extracts estimated, the lowest absorbance was detected for the ethanol extracts with the corresponding minimum peroxide formation at the time intervals observed. As seen in other antioxidant activities, the extracts with greater flavonoid or phenolic constituents showed lower absorbance as a result of minimum peroxidation. The antioxidant activities of extracts are largely dependent upon the solvent used, due to the diverse antioxidant potentials of the compounds with varying polarity [33]. Phenolic compounds are commonly credited for the antioxidant activities of most plant extracts [34]. The phenolic contents of plants are also dependent on the solvent types, the polarity and a number of intrinsic (i.e. genetic) and extrinsic factors, such as environmental, developmental stage and handling methods [35].

\section{Conclusions}

The extracting solvents considerably affected the phytochemistry and antioxidant activities of the extracts. The results showed that ethanol (absolute and 50\% diluted) had the maximum concentration of phytochemicals, which correlated well with the antioxidant results. The ethanol extracts also showed the highest antioxidant capabilities based on the DPPH, $\mathrm{H}_{2} \mathrm{O}_{2}$ radicals scavenging and FRAP assays. Thus, it can be concluded that the extracts obtained using high polarity solvent, like ethanol, were comparatively more effective radical scavengers than those using less polarity solvents, such as acetone and petroleum ether.

\section{Ethical Considerations}

\section{Compliance with ethical guidelines}

The study is an in vitro one which did not involve animals and human subjects. All ethical principles of chemicals and plants studies were applied in this research.

\section{Funding}

This research did not receive any specific grant from funding agencies in the public, commercial, or not-forprofit sectors.

\section{Conflict of interest}

The authors declared no conflict of interest.

\section{Acknowledgements}

The technical assistant of Mrs. E. O. Okoro of Medical Biochemistry Department, Delta State University is highly appreciated.

\section{References}

[1] Halliwell B. Oxidative stress and cancer: Have we moved forward? Biochem J. 2007; 401(1):1-11. [DOI:10.1042/ BJ20061131] [PMID]

[2] Lee HS. Antioxidant activity of browning reaction product isolated from storage-aged orange juice. J Agricul Food Chem. 1992; 40(4):550-2. [DOI:10.1021/jf00016a004]

[3] Ferguson LR. Chronic inflammation and mutagenesis. Mutat Res Fund Mol. 2010; 690(1-2):3-11. [DOI:10.1016/j.mrfmmm.2010.03.007] [PMID]

[4] Mbaebe BO, Edeoga HO, Afolayan AJ. Phytochemical analysis and antioxidants activities of aqueous stem bark extract of Schotia latifolia Jacq. Asian Pac J Trop Biomed. 2012; 2(2):118-24. [DOI:10.1016/S2221-1691(11)60204-9]

[5] Saeed M, Khan MR, Shabbir M. Antioxidant activity, total phenolic and total flavonoid contents of whole plant extracts Torilis leptophylla L. BMC Complement Altern Med. 2012; 12:221. [DOI:10.1186/1472-6882-12-221] [PMID] [PMCID]

[6] Chukwujekwu JC, Amoo SO, Van Staden J. Antimicrobial, antioxidant, mutagenic and antimutagenic activities of Distephanus angulifolius and Ormocarpum trichocarpum. J Ethnopharmacol. 2013; 148(3):975-9. [DOI:10.1016/j. jep.2013.06.003] [PMID]

[7] Montagnac JA, Davis CR, Tanumihardjo SA. Nutritional value of cassava for use as a staple food and recent advances for improvement. Compr Rev Food Sci Food Saf. 2009; 8(3):181-94. [DOI:10.1111/j.1541-4337.2009.00077.x]

[8] Bouis HE, Welch RM. Biofortification - a sustainable agricultural strategy for reducing micronutrient malnutrition in the global south. Crop Sci. 2010; 50(Suppl. 1):S20-S32. [DOI:10.2135/cropsci2009.09.0531]

[9] Howard Bradbury J, Denton IC. Mild methods of processing cassava leaves to remove cyanogens and conserve key nutrients. Food Chem. 2011; 127(4):1755-9. [DOI:10.1016/j. foodchem.2011.02.053] 
[10] Miladiyah I, Dayi F, Desrini S. Analgesic activity of ethanolic extract of Manihot esculenta Crantz leaves in mice. Univ Med. 2011; 30:3-10.

[11] Shaheen Khan M, Khan Yusufzai S, Kimin L, Binti Jabi NAN. Determination of chemical composition, total flavonoid content, total phenolic content and antioxidant capacity of various crude extracts of Manihot esculenta Crantz leaves. Int J Res Appl Sci Eng Technol. 2018; 6(4):2433-43. [DOI:10.22214/ijraset.2018.4413]

[12] Linn KZ, Myint PP. Estimation of nutritive value, total phenolic content and in vitro antioxidant activity of Manihot esculenta Crantz. (Cassava) leaf. J Med Plants. 2018; 6(6):73-8

[13] Liu W, Yin D, Li N, Hou X, Wang D, Li D, et al. Influence of environmental factors on the active substance production and antioxidant activity in potentilla fruticosa L. and its quality assessment. Sci Rep. 2016; 6:28591. [DOI:10.1038/srep28591] [PMID] [PMCID]

[14] Zhang Q. Effects of extraction solvents on phytochemicals and antioxidant activities of walnut (Juglans regia 1) green husk extracts. Eur J Food Sci and Technol. 2015; 3(5):15-21.

[15] Zhou K, Yu L. Effects of extraction solvent on wheat bran antioxidant activity estimation. LWT Food Sci Technol. 2004; 37(7):717-21. [DOI:10.1016/j.lwt.2004.02.008]

[16] Sultana B, Anwar F, Ashraf M. Effect of extraction solvent/ technique on the antioxidant activity of selected medicinal plant extracts. Molecules. 2009; 14(6):2167-80. [DOI:10.3390/ molecules14062167] [PMID] [PMCID]

[17] Sofowara A. Medical plants and tropical medicine in Africa. Ibandan, Nigeria: Spectrum Books Ltd; 1993.

[18] Trease G, Evans SM. Pharmacognosy 15 ed. London: Bailer Tindal; 2002.

[19] Harborne JB. Phytochemical methods - a guide to modern techniques of plant analysis. London: Chapman and Hall; 1984.

[20] Villaño D, Fernández-Pachón MS, Moyá ML, Troncoso AM, García-Parrilla MC. Radical scavenging ability of polyphenolic compounds towards DPPH free radical. Talanta 2007; 71(1):230-5. [DOI:10.1016/j.talanta.2006.03.050] [PMID]

[21] Bozin B, Mimica-Dukic N, Samojlik I, Goran A, Igicd R. Phenolics as antioxidants in garlic (Allium sativum L., Alliaceae). Food Chem. 2008; 111(4):925-9. [DOI:10.1016/j.foodchem.2008.04.071]

[22] Zhao H, Fan W, Dong J, Lu J, Chen J, Shan L, et al. Evaluation of antioxidant activities and total phenolic contents of typical malting barley varieties. Food Chem. 2008; 107(1):296304. [DOI:10.1016/j.foodchem.2007.08.018]

[23] Zou Y, Lu Y, Wei D. Antioxidant activity of a flavonoidrich extract of Hypericum perforatum L. In vitro. J Agric Food Chem. 2004; 52(16):5032-9. [DOI:10.1021/jf049571r] [PMID]

[24] Proestos Ch, Lytoudi K, Mavromelanidou OK, Zoumpoulakis P, Sinanoglou VJ. Antioxidant capacity of selected plant extracts and their essential oils. Antioxidants. 2013; 2(1):11-22. [DOI:10.3390/antiox2010011] [PMID] [PMCID]

[25] Benedec D, Vlase L, Oniga I, Mot AC, Damian G, Hanganu $\mathrm{D}$, et al. Polyphenolic composition, antioxidant and antibacterial activities for two Romanian subspecies of Achillea dis- tans Waldst. et Kit. ex Wild. Molecules. 2013; 18(8):8725-39. [DOI:10.3390/molecules18088725] [PMID] [PMCID]

[26] Vishnu Chandran R, Nisha R, Jamuna S, Paulsamy S. Quantification of total phenolics and flavonoids and evaluation of in vitro antioxidant properties of methanolic leaf extract of Tarenna asiatica - an endemic medicinal plant species of Maruthamali hills, Western Ghats, Tami Nadu. J Res Plant Sci. 2013; 2(2):196-204.

[27] Dvorakova M, Moreira MM, Dostalek P, Skulilova Z, Guido LF, Barros AA. Characterization of monomeric and oligomeric flavan-3-ols from barley and malt by liquid chromatography-ultraviolet detection-electrospray ionization mass spectrometry. J Chromatogr A. 2008; 1189(1-2):398-405. [DOI:10.1016/j.chroma.2007.10.080] [PMID]

[28] Naczk M, Shahidi F. Phenolics in cereals, fruits and vegetables: Occurrence, extraction and analysis. J Pharm Biomed Anal. 2006; 41(5):1523-42. [DOI:10.1016/j.jpba.2006.04.002] [PMID]

[29] Gulcin I, Berashvili D, Gepdiremen A. Antiradical and antioxidant activity of total anthocyanins from Perilla pankinensis decne. J Ethnopharmacol. 2005; 101(1-3):287-93. [DOI:10.1016/j.jep.2005.05.006] [PMID]

[30] Dai J, Mumper RJ. Effect of extraction solvent/technique on the antioxidant activity of selected medicinal plant extracts. Molecules. 2009; 14(6):2167-80. [DOI:10.3390/molecules14062167] [PMID] [PMCID]

[31] Muller L, Frohlich K, Bohm V. Comparative antioxidant activities of carotenoids measured by ferric reducing antioxidant power (FRAP), ABTS bleaching assay (aTEAC), DPPH assay and peroxyl radical scavenging assay. Food Chem 2011; 129(1):139-48. [DOI:10.1016/j.foodchem.2011.04.045]

[32] Purena R, Bhatt R. Comparative phytochemical investigation, antioxidant and anticancer properties of leave extracts of four medicinal plants from Chhattisgarh, India. Asian J Plant Sci Res. 2018; 8(3):1-21.

[33] Marinova EM, Yanishlieva NV.. Antioxidative activity of extracts from selected species of the family Lamiaceae in sunflower oil. Food Chem. 1997; 58(3):245-8. [DOI:10.1016/ S0308-8146(96)00223-3]

[34] Dai J, Mumper RJ. Plant phenolics: Extraction, analysis and their antioxidant and anticancer properties. Molecules. 2010; 15(10):7313-52. [DOI:10.3390/molecules15107313] [PMID] [PMCID]

[35] Fratianni F, Tucci M, De-Palma M, Pepe R, Nazzaro F. Polyphenolic composition in different parts of some cultivars of globe artichoke (Cynara cardunculus L. var. scolymus (L.) Fiori). Food Chem. 2007; 104(3):1282-6. [DOI:10.1016/j.foodchem.2007.01.044] 